\title{
Modifikasi Medium Menggunakan Saline-Water Soluble Fraction (SSF) atau Fraksi Minyak Terlarut untuk Menumbuhkan Bakteri Pendegradasi Hidrokarbon
}

\author{
Huyyirnah ${ }^{1^{*}}$, Rosmaniar $\mathbf{R}^{2}$ \\ 1 Huyyirnah, FIKP, Universitas Hasanuddin, Makassar, 90245, huyyirnah@yahoo.com \\ 2 Rosmaniar R, FIKP, Universitas Hasanuddin, Makassar, 90245, \\ rosmaniar756@gmail.com
}

Submisi: 21 September 2021; Penerimaan: 3 Desember 2021

\begin{abstract}
ABSTRAK
Isolasi bakteri pendegradasi hidrokarbon memerlukan teknik yang baik dan nutrisi optimal untuk pertumbuhannya. Kendala dalam pembuatan medium dan pengamatan isolat bakteri yang mengandung hidrokarbon sering terjadi di laboratorium, sehingga dibutuhkan teknik pengembangan metode dalam proses isolasi bakteri pendegradasi hidrokarbon. Penelitian ini bertujuan untuk mengetahui dan membandingkan jumlah dan jenis koloni bakteri yang tumbuh dalam medium Zobell+saline-water soluble fraction (SSF) dibandingkan dengan medium Zobell+minyak bumi. Metode penelitian yaitu mengisolasi bakteri menggunakan medium Zobell+SSF 6 jam (A), 12 jam (B), 24 jam (C) dan sebagai kontrol adalah medium Zobell $+1 \%$ V/v minyak bumi (K), perhitungan bakteri menggunakan metode TPC dan mengidentifikasi bakteri dengan alat VITEK-MS. Hasil penelitian memperlihatkan bahwa jumlah bakteri yang tumbuh pada medium Zobell+SSF 24 jam (C) adalah $6.9 \times 10^{8} \mathrm{CFU} / \mathrm{ml}$, hal ini menunjukkan lebih baik dibandingkan dengan Zobell $+1 \% \mathrm{v} / \mathrm{v}$ minyak bumi $(\mathrm{K})=5.2 \times 10^{8} \mathrm{CFU} / \mathrm{ml}$, medium Zobell+SSF 12 jam $(B)=6.6 \times 10^{7} \mathrm{CFU} / \mathrm{ml}$ dan medium Zobell+SSF $6 \mathrm{jam}(A)=1.8 \times 10^{7} \mathrm{CFU} / \mathrm{ml}$. Kesimpulan penelitian ini adalah bahwa dari segi jumlah total bakteri medium modifikasi Zobell+SSF pengadukan selama 24 jam (C) lebih baik dalam menumbuhkan bakteri pendegradasi hidrokarbon dibandingkan dengan pengadukan 6 jam (A), 12 jam (B), dan medium Zobell $+1 \% \mathrm{~V} / \mathrm{v}$ minyak bumi (K). Sedangkan apabila berdasarkan dengan keragaman bakteri, didapatkan hasil bahwa strain bakteri yang terisolasi pada medium modifikasi Zobell+SSF perlakuan pengadukan $6,12,24$ jam sama dengan strain bakteri yang tumbuh pada kontrol (medium Zobell $+1 \%$ v/v minyak bumi. Bakteri yang teridentifikasi sebagai bakteri pendegaradsi hidrokarbon adalah bakteri Klebsiella pneumoniae, Enterobacter asburiae/Enterobacter cloacae dan Pseudomonas aeruginosa.
\end{abstract}

Kata kunci: Saline-water Soluble Fraction; medium; bakteri; hidrokarbon

\section{PENDAHULUAN}

\section{Latar Belakang}

Kondisi lingkungan perairan yang tercemar minyak, solar dan senyawa hidrokarbon lainnya menarik untuk dikaji baik dari segi kondisi sebab internal maupun eksternal, akibat atau dampak yang terjadi ataupun bahkan pemanfaatan mikroorganisme yang bersinergi di dalam lingkungan tersebut.

Kajian tentang kondisi dan aktifitas bakteri pendegradasi di lingkungan laut dirangkum dalam mata kuliah Bioremediasi yang disajikan sebagai mata kuliah pilihan bagi mahasiswa Departemen IImu Kelautan, 
Fakultas IImu Kelautan dan Perikanan Universitas Hasanuddin. Hal yang sering dijadikan topik dalam penelitian adalah pemanfaatan bakteri yang dapat dijadikan kandidat mikrorganisme pendegradasi hidrokarbon, dimana isolasi bakteri ini memerlukan teknik yang baik dan media nutrisi yang cukup untuk bakteri tersebut. Metode yang sering digunakan oleh peneliti dan mahasiswa adalah metode berdasarkan beberapa literatur penelitian yaitu teknik isolasi dan permurnian bakteri menggunakan medium padat yaitu seperti medium Zobell+minyak bumi (Gosalam, 1999; Munawar, 1999).

Berdasarkan pengalaman di laboratorium Mikrobiologi Laut, secara teknis penambahan minyak bumi ke dalam medium padat akan menghasilkan medium yang tidak bercampur homogeny. Setelah penambahan secara langsung berupa crude oil atau minyak bumi dalam medium terkadang akan tertutupi oleh minyak bumi tersebut dan berwarna coklat kehitaman, dan tentu saja akan mengalami kesulitan dalam pengamatan koloni bakteri yang tumbuh seperti pada penelitiah yang telah dilakukan sebelumnya oleh Azhari (2008) dan Afrisal, dkk (2014).

Maka penting untuk dilakukan penelitian berupa pengembangan kinerja metode di laboratorium dengan melakukan modifikasi pada pembuatan medium dengan judul 'Modifikasi Medium Menggunakan Saline-water Soluble Fraction (SSF) atau Fraksi Minyak Terlarut untuk Menumbuhkan Bakteri Pendegradasi Hidrokarbon'.

\section{Tujuan Penelitian}

Penelitian ini bertujuan untuk mengetahui dan membandingkan jumlah dan jenis koloni bakteri yang tumbuh dalam medium Zobell+salinewater soluble fraction (SSF) dibandingkan dengan medium
Zobell+minyak bumi dan mengidentifikasi bakteri tumbuh.

\section{METODE PENELITIAN}

\section{Waktu dan Tempat}

Penelitian ini dilaksanakan mulai dari bulan Juni - Agustus 2021. Pengambilan sampel dilakukan diperairan Pelabuhan Paotere kota Makassar. Kegiatan isolasi dan pemurnian bakteri dilakukan di laboratorium Mikrobiologi Laut Fakultas IImu Kelautan dan Perikanan, identifikasi bakteri dilakukan di laboratorium Balai Kesehatan Makassar.

\section{Alat dan Bahan}

Alat-alat yang digunakan dalam pengembangan profesi ini adalah autoklaf (All American), inkubator (Imperial III), laminar air flow (Envirco), VITEK-MS, hot plate with magnetic stirrer (EBA), mikropipet (Socorex), mikroskop (Olympus CX 22), oven (Jumo), vortex (IKA), timbangan analitik (Sartorius) cawan petri $(\varnothing 90 \mathrm{~mm}$, Pyrex), corong pisah, statis dan klem, labu Erlenmeyer (Pyrex), gelas piala (Pyrex), gelas ukur (Pyrex), corong, tabung reaksi.

Bahan-bahan yang digunakan adalah $\mathrm{CaCl}_{2}$ (Merck, p.a), MgSO4.7 $\mathrm{H}_{2} \mathrm{O}$ (Merck, p.a), $\mathrm{K}_{2} \mathrm{HPO}_{4}$ (Merck, p.a), $\mathrm{KH}_{2} \mathrm{PO}_{4}$ (Merck, p.a), $\mathrm{NH}_{4} \mathrm{NO}_{3}$ (Merck, p.a), 60\% $\mathrm{FeCl}_{3}$ (Merck, p.a), Pepton (Merck), ekstrak ragi (Merck), $\mathrm{KNO}_{3}$ (Merck, p.a), sampel air laut dari perairan yang tercemar minyak, minyak bumi dan air laut.

\section{Prosedur Penelitian}

\section{Pembuatan Saline-water soluble fraction of Crude Oil (SSF)}

Memasukkan $10 \mathrm{ml}(1 \% \mathrm{v} / \mathrm{v})$ minyak bumi ke dalam $1000 \mathrm{ml}$ air laut steril di dalam labu Erlenmeyer dan distirer selama 6 jam, 12 jam, 
24 jam. Selanjutnya masing-masing larutan dalam Erlenmeyer dipisahkan bagian minyak yang tidak larut dengan menggunakan corong pisah ukuran $250 \mathrm{ml}$. Cairan bagian bawah adalah bagian fraksi minyak terlarut yang telah mengandung kandungan hidrokarbon terlarut yang dapat digunakan dalam pembuatan medium padat untuk menumbuhkan bakteri pendegradasi hidrokarbon yang selanjutnya di sebut sebagai larutan Saline-water soluble fraction of Crude Oil (SSF). Larutan SSF ini selanjutnya akan diuji kandungan kimianya antara lain parameter sulfur, nitrat, fosfat dan salinitas dan oil content.

\section{Pembuatan Medium Modifikasi}

Medium yang digunakan pada tahap isolasi enrichment adalah medium Bushnell Haas Mineral Salt (BHMS) cair yang terdiri dari $0,02 \mathrm{~g}$ $\mathrm{CaCl}_{2}, 0,2 \mathrm{~g} \mathrm{MgSO} 4.7 \mathrm{H}_{2} \mathrm{O}, 1 \mathrm{~g}$ $\mathrm{K}_{2} \mathrm{HPO}_{4}, 1 \mathrm{~g} \mathrm{KH}_{2} \mathrm{PO}_{4}, 1 \mathrm{~g}$ $\mathrm{NH}_{4} \mathrm{NO}_{3}, 2$ tetes $60 \% \quad \mathrm{FeCl}_{3}$ dalam aquades hingga 1 liter.

Medium yang digunakan pada tahap pemurnian dan penghitungan bakteri adalah Medium Zobell yang terdiri dari $5.00 \mathrm{~g}$ pepton, $0,01 \mathrm{~g}$ eksrak ragi, $0,10 \mathrm{~g} \mathrm{~K}_{2} \mathrm{HPO}_{4}$ dan $0,10 \mathrm{~g} \mathrm{KNO}_{3}$ dalam $1 \mathrm{~L}$ pelarut SSF. Sehingga medium kerja yang dibuat adalah sebagai berikut: medium Zobell + SSF 6 jam (perlakuan A), medium Zobell + SSF 12 jam (B), medium Zobell + SSF 24 jam dan Medium Zobell + $10 \mathrm{ml}(1 \% \mathrm{v} / \mathrm{v})$ minyak bumi.

\section{Isolasi dan Pemurnian Bakteri Pendegradasi Hidrokarbon}

Sampel air laut sebanyak $10 \mathrm{ml}$ dimasukkan ke dalam medium kaldu BHMS kemudian diinkubasi pada suhu $30^{\circ} \mathrm{C}$ selama 3 hari dan dikocok dengan rotary shaker dengan kecepatan $120 \mathrm{rpm}$. Untuk membuat pengenceran $10^{-1}$, diambil $1 \mathrm{ml}$ dari larutan stok lalu dimasukkan ke dalam tabung reaksi yang berisi $9 \mathrm{ml}$ larutan fisiologis $\mathrm{NaCl}$ 0,9 \% kemudian diaduk dengan vortex. Selanjutnya diambil $1 \mathrm{ml}$ dari larutan pengenceran $10^{-1}$ lalu dimasukkan ke dalam tabung reaksi yang berisi $9 \mathrm{ml}$ larutan fisiologis $\mathrm{NaCl} 0,9 \%$ dan diaduk, ini merupakan larutan pengenceran $10^{-2}$. Dengan cara yang sama dilakukan seterusnya hingga pengenceran $10^{-8}$. Selanjutnya dilakukan penghitungan total bakteri dengan metode Angka Lempeng Total spread plate. Cawan-cawan petri yang berisi suspensi tersebut selanjutnya diinkubasi pada suhu $30^{\circ} \mathrm{C}$ selama 3 hari. Pemurniaan dilakukan dengan cara memisahkan koloni-koloni yang tumbuh pada lempeng agar Medium A, B, C dan K. Semua tahap pengerjaan ini dilakukan secara aseptik. Cawan-cawan petri tersebut kemudian diinkubasi pada suhu $30^{\circ} \mathrm{C}$ selama 3 hari.

4. Pengamatan Morfologi dan Perhitungan Jumlah Bakteri

Pengamatan morfologi koloni berdasarkan petunjuk (Cappuccino dan Sherman, 1986) yaitu dengan mengamati: bentuk, elevasi, tepi, tekstur, dan warna. Metode Perhitungan Jumlah bakteri yang digunakan adalah Angka Lempeng Total (ALT). Standar bakteri yang digunakan dalam perhitungan antara 20-250 koloni per cawan (BSN, 2006). 


\section{Pewarnaan Gram dan Pengamatan Morfologi Sel}

Membuat olesan tipis dari isolat murni bakteri pada gelas objek yang bersih, kemudian pengeringanginan. Setelah kering, dilakukan fiksasi dengan cara melewatkan bagian bawah gelas objek di atas api bunsen. Selanjutnya meneteskan larutan Kristal violet pada olesan bakteri dan didiamkan selama 1 menit. Membilas dengan air kran, pengering-anginan. Kemudian menetesi dengan larutan iodine dan dibiarkan selama 1 menit. Membilas dengan air kran, pengering-anginan. Meneteskan dengan alkohol 95\% selama 30 detik. Membilas dengan air kran, selanjutnya dilakukan pengeringanginan. Menetes dengan safranin selama 1 menit, kemudian membilas dengan air kran selama beberapa detik. Mengamati hasil pewarnaan dibawah mikroskop dengan pembesaran $10 \times 100$ menggunakan minyak imersi. Selsel bakteri Gram positif akan berwarna ungu hingga biru, sedangkan sel bakteri bakteri Gram negatif akan berwarna merah. Mengamati morfologi sel sehingga dapat diketahui bentuknya (kokus, batang atau spiral) (Cappuccino dan Sherman, 1986).

\section{Identifikasi Bakteri Dengan VITEK-MS \\ VITEK-MS adalah alat untuk mengidentifikasi bakteri secara automatik dengan metode pemeriksaan mikrobiologi}

menggunakan prinsip Mass Spectometry. Prosedur persiapan sampel adalah sebagai berikut: menginokulasikan sampel bakteri pada suhu $30^{\circ} \mathrm{C}$ selama 24 jam. Selanjutnya mengambil isolat murni menggunakan ose dan menempatkan koloni di tengah posisi spot dan meratakannya. Menambahkan matrix $1 \mu \mathrm{l}$ VITEK $\mathrm{MS}-\mathrm{CHCH}$ di tengah posisi spot menggunakan mikropipet. Pastikan seluruh deposit tertutup oleh matrix. Biarkan spot mengering secara menyeluruh. Selanjutnya memproses slide pada instrumen VITEK-MS. Pembacaan hasil dilakukan dengan menggunakan alat bantu komputer. Hasil uji akan muncul di monitor yang terhubung dengan VITEK-MS berupa nama spesies sampel yang diuji.

\section{Analisis Data}

Analisis data yang digunakan dalam penelitian ini menggunakan deskriptif kualitatif terhadap hasil pengamatan isolat bakteri yang diduga bakteri pendegradasi hidrokarbon. Data yang diperoleh dari penelitian ini ditampilkan dalam bentuk tabel, dan gambar.

\section{HASIL DAN PEMBAHASAN}

\section{Saline-water soluble fraction of Crude Oil (SSF).}

Saline-water soluble fraction of Crude Oil (SSF) yang dihasilkan dari penelitian ini ditampilkan pada Gambar 1. 


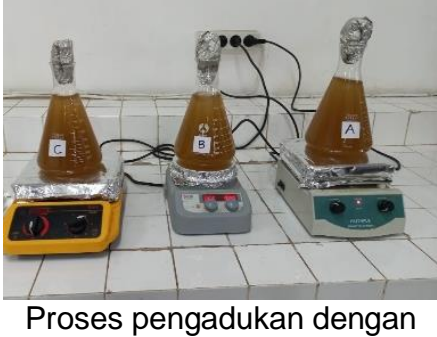
alat magnetik strirrer selama 6 12, dan 24 jam

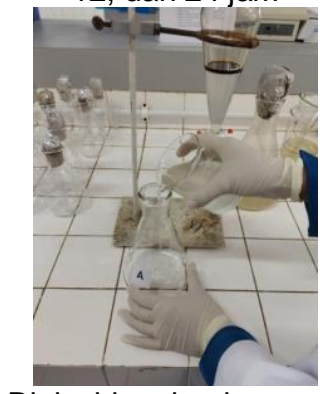

Dipisahkan bagian yang terpisah dari minyak
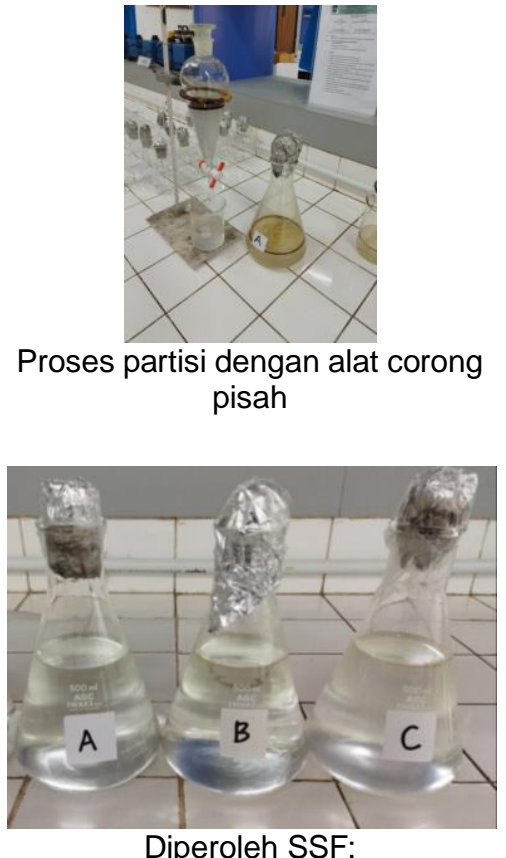

A. Pengadukan 6 jam

B. Pengadukan 12 jam

C. Pengadukan 24 jam

Gambar 1. Proses pembuatan Saline-water soluble fraction of Crude Oil (SSF)

\section{Pengukuran parameter Saline-water soluble fraction of Crude Oil (SSF). \\ Pengukuran parameter Saline- water soluble fraction of Crude Oil (SSF) memberikan hasil seperti pada Tabel 1.}

Secara teknis pengadukan dengan bantuan magnetik stirrer diharapkan dapat membantu proses perombakan senyawa hidrokarbon dalam air laut sehingga proses pelarutan dapat terjadi lebih maksimal. Bagian minyak yang terlarut diharapkan menjadi nutrisi bagi mikroorganisme yang memerlukan senyawa hidrokarbon sebagai unsur makanannnya. Proses secara kinetik dalam jangka waktu 12 jam telah dilakukan pula oleh Loya dan Rinkevich (1979) pada penelitian tentang pengaruh keberadaan crude oil terhadap karang.

Menurut Wenti (2012) suhu dapat mempengaruhi lingkungan dan aktivitas atau populasi mikroorganisme. Umumnya kecepatan degradasi minyak hidrokarbon oleh bakteri aerob berlangsung optimum pada suhu berkisar antara $15-30^{\circ} \mathrm{C}$ (Zam, 2010). Kemudian Prasetya dkk (2016) menyatakan bahwa bakteri yang berpotensi mendegradasi senyawa sulfur aromatik minyak hidrokarbon tumbuh dengan baik pada kisaran suhu $30^{\circ} \mathrm{C}$.

Derajat keasaman $(\mathrm{pH})$ berkisar antara 6,2 - 7,9. $\mathrm{pH}$ merupakan salah satu faktor yang mempengaruhi laju pertumbuhan mikroba dan berkaitan dengan aktivitas enzim, Umumnya enzim bekerja optimum pada rentang pH 6-8. Menurut Wenti (2012) tingkat optimal pertumbuhan dan biodegradasi hidrokarbon dapat berlangsung pada keadaan yang cukup nutrisi, oksigen yang cukup dan $\mathrm{pH}$ antara 6 dan 9 . 
Tabel 1. Parameter pengukuran Saline-water soluble fraction of Crude Oil (SSF)

\begin{tabular}{cccccc}
\hline & & \multicolumn{4}{c}{ Saline-water soluble fraction of Crude Oil (SSF) } \\
\cline { 3 - 6 } No & Parameter & $\begin{array}{c}\mathrm{A} \\
(6 \mathrm{jam})\end{array}$ & $\begin{array}{c}\mathrm{B} \\
(12 \text { jam) }\end{array}$ & $\begin{array}{c}\mathrm{C} \\
(24 \text { jam })\end{array}$ & $\begin{array}{c}\mathrm{K} \\
\text { (Medium }+1 \% \mathrm{w} / \mathrm{v} \\
\text { minyak bumi) }\end{array}$ \\
\hline 1 & Salinitas (ppt) & 33 & 33 & 33 & 33 \\
2 & Suhu (ㅇ) & 28 & 28 & 28 & 28 \\
3 & $\mathrm{pH}$ & 7,0 & 7,0 & 7,2 & 7,2 \\
4 & Sulfat (ppm) & 134,96 & 103,93 & 123,66 & 137,01 \\
5 & Nitrat (ppm) & 0,756 & 0,233 & 1,028 & 1,697 \\
6 & Fosfat (ppm) & 6,011 & 6,430 & 7,484 & 6.140 \\
7 & Oil (ppm) & 0.138 & 0.281 & 0.483 & 1,133 \\
\hline
\end{tabular}

\section{Jumlah Bakteri Pendegaradsi Hidrokarbon}

Jumlah bakteri pendegradasi minyak hidrokarbon pada medium $\mathrm{K}$ dan $\mathrm{C}$ terlihat hampir sama dan lebih tinggi bila dibandingkan dengan jumlah bakteri pada medium A dan B. Menurut Elyza dkk., (2015) laju pertumbuhan bakteri tergantung dengan kondisi substratnya. Apabila kondisi substratnya sesuai, maka laju pertumbuhannya akan dominan, sebaliknya apabila kondisi substrat tidak sesuai maka laju pertumbuhannya akan lambat.

Hal ini dapat juga disebabkan karena pengaruh beberapa faktor, salah satunya adalah unsur-unsur nutrien. Nutrien harus ada di lingkungan tenpat mikroorganisme itu dibiakkan atau setidaknya ditambahkan ke dalam lingkungan tersebut agar mikroorganisme dapat berkembang biak dengan cepat dan degradasi bahan organik, terutama karbonnya sebagai sumber energi (Widjayanti dkk., 2010).

Penampakan koloni bakteri pada modifikasi medium menggunakan Saline-water soluble fraction of Crude Oil (SSF) terlihat lebih jelas dan pengamatan terhadap koloni lebih efisien dan mudah, bila dibandingkan dengan koloni pada medium yang menggunakan langsung $1 \% \mathrm{v} / \mathrm{v}$ minyak bumi dalam medium tersebut. Penampakan koloni dapat dilihat pada gambar 2.

Tabel 2. Jumlah Rata-rata Bakteri Pendegradasi Hidrokarbon pada Masingmasing Medium Modifikasi SSF

\begin{tabular}{|c|c|}
\hline Medium & $\begin{array}{c}\text { Jumlah Bakteri } \\
\text { (CFU/ml) }\end{array}$ \\
\hline $\begin{array}{c}\text { Zobell } A+\text { SSF } 6 \\
\text { jam }\end{array}$ & $1.8 \times 10^{7}$ \\
\hline $\begin{array}{c}\text { Zobell B + SSF } 12 \\
\text { jam }\end{array}$ & $6.6 \times 10^{7}$ \\
\hline $\begin{array}{c}\text { Zobell C }+ \text { SSF } 24 \\
\text { jam }\end{array}$ & $6.9 \times 10^{8}$ \\
\hline $\begin{array}{c}\text { Zobell }+1 \% \mathrm{v} / \mathrm{v} \\
\text { minyak bumi }\end{array}$ & $5.2 \times 10^{8}$ \\
\hline
\end{tabular}

\section{Morfologi Koloni Bakteri Pendegradasi Hidrokarbon} Hasil pengamatan morfologi koloni 6 isolat bakteri yang berhasil diisolasi dapat dilihat pada Tabel 3.

Pengamatan morfologi koloni bakteri menunjukkan hanpir tidak ada perbedaan antara 6 isolat tersebut. Umumnya isolat berbentuk tak beraturan dan bulat, memiliki warna putih dan krem dengan tepian rata dan bergelombang dan sebagian besar elevasi timbul serta ada yang datar. 


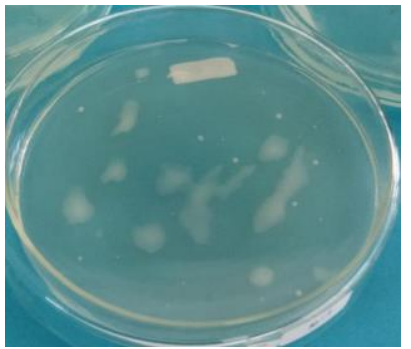

Zobell A + SSF 6 jam

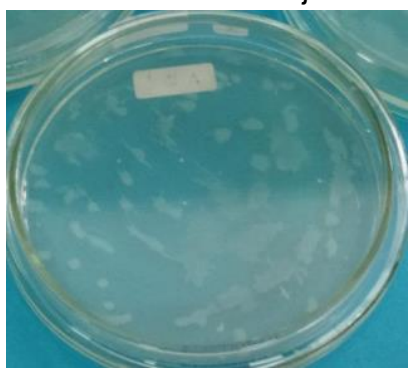

Zobell C + SSF 24 jam

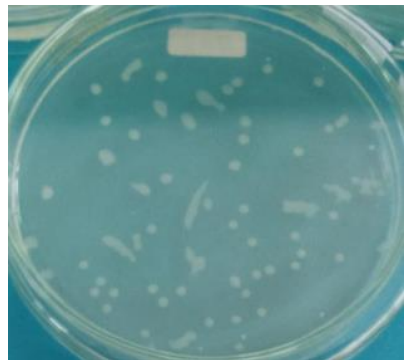

Zobell B + SSF 12 jam

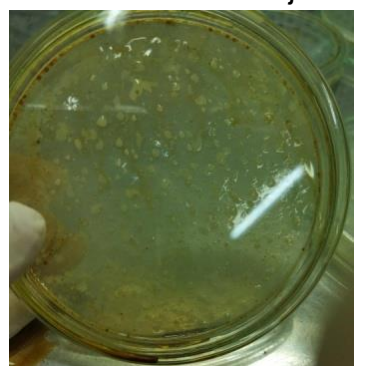

Zobell $+1 \% \mathrm{v} / \mathrm{v}$ minyak bumi

Gambar 2. Penampakan koloni bakteri pada medium modifikasi Zobell + SSF dan $+1 \%$ $\mathrm{v} / \mathrm{v}$ minyak bumi

Tabel 3. Morfologi Koloni Bakteri Pendegradasi Hidrokarbon

\begin{tabular}{ccccc}
\hline Kode Isolat & Bentuk koloni & Tepian & Elevasi & Warna \\
\hline $\mathbf{1}$ & Tidak beraturan & Bergelombang & Timbul & Putih \\
$\mathbf{2}$ & Bulat & Rata & Timbul & Putih \\
$\mathbf{3}$ & Tidak beraturan & Bergelombang & Datar & Krem \\
$\mathbf{4}$ & Bulat & Rata & Timbul & Putih \\
$\mathbf{5}$ & Bulat & Rata & Timbul & Putih \\
$\mathbf{6}$ & Bulat & Rata & Timbul & Krem \\
\hline
\end{tabular}

\section{Identifikasi bakteri dengan Vitek}

Hasil identifikasi isolat bakteri dengan Vitek dapat diihat pada Tabel 4.

Isolat bakteri yang berhasil di identifikasi adalah isolat 2, 4 dan 6 yang berturut-turut teridentifikasi sebagai bakteri Klebsiella pneumoniae, Enterobacter

asburiae/Enterobactercloacae dan Pseudomonas aeruginosa. Sejalan dengan penelitian Manalu dkk (2016), yang mengeksplorasi bakteri pendegradasi hidrokarbon pada tanah yang terkontaminasi minyak bumi, telah berhasil mengisolasi bakteri yang sama yaitu Klebsiella pneumoniae dan Pseudomonas aeruginosa.

Bakteri Enterobacter asburiae dan Enterobacter cloacae yang berhasil diisolasi dari penelitian ini dengan prediksi 50\%:50\%, juga telah diteliti oleh Abraham dan Silambarasan (2015) yang menyatakan bahwa bakteri ini memiliki potensi biodegradasi senyawa ensosulfan dan bakteri tersebut berpotensi sebagai agen bioremediasi dari daerah yang tercemar.

\section{Hubungan Antara Medium Modifikasi dengan Jumlah dan Jenis Bakteri Pedegradasi Yang Tumbuh}

Dari uraian di atas, terlihat bahwa bakteri pendegaradasi hidrokarbon yang dapat tumbuh pada medium modifikasi Zobell + Saline-water soluble fraction (SSF) adalah sebagai berikut, yaitu pada medium $\mathrm{C}$ dan $\mathrm{K}$ terdapat tumbuh 6 macam isolat bakteri, sedangkan pada 
medium $A=2$ macam dan medium $B=3$ macam isolat bakteri. Jumlah bakteri juga terlihat relatif lebih tinggi yang tumbuh pada medium $\mathrm{C}$ yaitu $6.9 \times 10^{8}$
$\mathrm{CFU} / \mathrm{ml}$, dibandingkan dengan medium $\mathrm{A}=1.8 \times 10^{7}, \mathrm{~B}=6.6 \times 10^{7}$ dan $\mathrm{K}=5.2 \times$ $10^{8}$.

Tabel 4. Identifikasi Bakteri dengan VITEK MS

\begin{tabular}{ccccc}
\hline $\begin{array}{c}\text { Kode } \\
\text { Isolat }\end{array}$ & Bentuk sel & Gram & Akurasi & Spesies \\
\hline 1 & Coccus & Negatif & - & Tidak teridentifikasi \\
2 & Basil & Negatif & $99.9 \%$ & Klebsiella pneumoniae \\
3 & Basil & Negatif & - & Tidak teridentifikasi \\
4 & Basil & Negatif & $50 \%$ & Enterobacter asburiae/ \\
& & & $50 \%$ & Enterobacter cloacae \\
5 & Basil & Negatif & - & Tidak teridentifikasi \\
6 & Basil & Negatif & $99.9 \%$ & Pseudomonas aeruginosa \\
\hline
\end{tabular}

Tabel 5. Hubungan Antara Medium Modifikasi dengan Jumlah dan Jenis Bakteri yang Tumbuh

\begin{tabular}{|c|c|c|c|}
\hline Medium Modifikasi & $\begin{array}{c}\text { Jumlah ALT } \\
\text { (CFU/ml) }\end{array}$ & $\begin{array}{c}\text { Jumlah Isolat } \\
\text { Bakteri Yang } \\
\text { Tumbuh }\end{array}$ & Jenis Bakteri \\
\hline Zobell + SSF 6 jam (A) & $1.8 \times 107$ & 2 & $\begin{array}{l}\text { Tidak teridentifikasi } \\
\text { Klebsiella pneumonia }\end{array}$ \\
\hline Zobell + SSF 12 jam (B) & $6.6 \times 107$ & 3 & $\begin{array}{c}\text { Tidak teridentifikasi } \\
\text { Klebsiella pneumoniae } \\
\text { Pseudomonas aeruginosa }\end{array}$ \\
\hline Zobell + SSF 24 jam (C) & $6.9 \times 108$ & 6 & $\begin{array}{l}\text { Tidak teridentifikasi } \\
\text { Klebsiella pneumoniae } \\
\text { Tidak teridentifikasi } \\
\text { Enterobacter asburiae/ } \\
\text { Enterobacter cloacae } \\
\text { Tidak teridentifikasi } \\
\text { Pseudomonas aeruginosa }\end{array}$ \\
\hline $\begin{array}{l}\text { Zobell }+10 \% \text { minyak } \\
\text { hidrokarbon }(\mathrm{K})\end{array}$ & $5.2 \times 108$ & 6 & $\begin{array}{c}\text { Tidak teridentifikasi } \\
\text { Klebsiella pneumoniae } \\
\text { Tidak teridentifikasi } \\
\text { Enterobacter asburiae/ } \\
\text { Enterobacter cloacae } \\
\text { Tidak teridentifikasi } \\
\text { Pseudomonas aeruginosa }\end{array}$ \\
\hline
\end{tabular}

\section{PENUTUP}

\section{Kesimpulan}

Hasil peneltian memperlihatkan bahwa dari segi jumlah total bakteri medium modifikasi Zobell+Saline-water soluble fraction of Crude Oil (SSF) dengan pengadukan selama 24 jam (C) lebih baik dalam menumbuhkan bakteri pendegradasi hidrokarbon dibandingkan dengan pengadukan 6 jam (A), 12 jam (B), dan medium Zobell $+1 \% \mathrm{v} / \mathrm{v}$ minyak bumi $(\mathrm{K})$, sedangkan apabila berdasarkan dengan keragaman bakteri, didapatkan hasil bahwa strain bakteri yang terisolasi pada medium modifikasi Zobell+SSF perlakuan stirrer 6, 12,24 jam sama dengan strain bakteri yang tumbuh pada kontrol (medium Zobell $+1 \% \mathrm{v} / \mathrm{v}$ minyak bumi.

Penampakan koloni yang tumbuh pada medium modifikasi Zobell+Salinewater soluble fraction of Crude Oil (SSF) lebih jelas dan lebih mudah dalam pengamatan morfologi koloni. Bakteri yang teridentifikasi sebagai bakteri 
pendegaradsi hidrokarbon adalah bakteri Klebsiella pneumoniae, Enterobacter asburiae/Enterobacter cloacae dan Pseudomonas aeruginosa.

\section{Saran}

Disarankan untuk penelitian lanjut, proses pelarutan minyak hidrokarbon selain dengan proses pengadukan, dapat lebih ditingkatkan dengan bantuan penambahan bahan pelarut yang aman atau dapat pula menggunakan alat sonikator.

\section{UCAPAN TERIMA KASIH}

Terima kasih dan penghargaan disampaikan kepada pihak Universitas Hasanuddin, juga kepada teman sejawat PLP Universitas Hasanuddin, serta berbagai pihak yang telah memungkinkan penelitian ini berlangsung. Penelitian ini didanai dari skim Pengembangan Profesi Tenaga Kependidikan Fungsional (PPTKF) Tahun 2021 oleh pihak Rektorat Universitas Hasanuddin.

\section{DAFTAR PUSTAKA}

Abraham J, Silambarasan S. Plant growth promoting bacteria Enterobacter asburiae JAS5 and Enterobacter cloacae JAS7 in mineralization of endosulfan. Appl Biochem Biotechnol.2015 Apr;175(7): 3336-48.doi: 10.1007/s12010-015-1504-7

Afrisal, dkk., 2014, Isolasi Bakteri Pendegradasi Minyak Oli HSFO di Laut Lampia, Kab. Luwu Timur. Penelitian Olimpiade Sains Nasional (OSN) Pertamina. Jurusan IImu Kelautan, Fakultas Ilmu Kelautan dan Perikanan, Universitas Hasanuddin, Makassar.

Azhari, Y., 2008, Uji Kemampuan Biodegradasi Senyawa Hidrokarbon Minyak Bumi Oleh Bakteri dari Sedimen Pelabuhan
Soekarno Hatta Kota Makassar. Skripsi. Jurusan IImu Kelautan, Fakultas IImu Kelautan dan Perikanan, Makassar.

Badan Standardisasi Nasional. 2006. Pengujian Angka Lempeng Total Produk Perikanan. SNI 012332.3-2006.

Cappucino, J.G. and N. Sherman., 1986. Microbiology: A Laboratory Mannual. The Benyamin/Cummings Publish, California.

Elyza F, N. Gofar, Munawar.2015. Identifikasi dan Uji Potensi Bakteri Lipolitik dari Limbah SBE (Spent Bleaching Earth) Sebagai Agen Bioremediasi. Jurnal IImu Lingkungan 13 (1): 12-18.

Gosalam, S., 1999, Uji Kemampuan Bakteri dari Ekosistem Mangrove dengan Perlakuan Pemupukan dalam Mendegradasi Residu Minyak Bumi. Tesis. Magister Program Pasca Sarjana ITB. Bandung.

Loya, Y. and B. Rinkevich., 1979. Abortion Effect in Coral Induced by Oil Pollution. Marine Ecology Progress Series. Vol 1, 77-80.

Manalu, R.T. Napoleon, A. Hermawan, A, 2016. Eksplorasi Bakteri Pendegradasi Hidrokarbon Pada Tanah Terkontaminasi Minyak Bumi.Saintech Farma Vol. 9 No.2, Juli 2016. 39-42.

Munawar, S.P. Estuningsih, B. Yudono, M. Said, Salni. 2008. Studi Penggunaan Bakteri Indigen Petrofilik dalam Proses Bioremediasi Minyak Bumi di Wilayah Sumatera Bagian Selatan. Makalah seminar PITPERMI, Purwokerto.

Nugroho, A. 2006. Biodegradasi Sludge Minyak Bumi Dalam Skala Mikrokosmos: Simulasi Sederhana Sebagai Kajian Awal Bioremediasi Land Treatment. Makara Teknologi. 10 (2): 82-89.

Prasetya I.P.H, I.B.W. Gunam, N.S. Antara. 2016. Isolasi Bakteri Potensial Pendegradasi Dibenzotiofena dari Tanah Tercemar Minyak Bumi di Buluh 
Telang Langkat Sumatera Utara. Artikel Teknologi Pertanian Unud.

Sharpley, J.M, 1966. Elementary Petroleum Microbiology, Gulf Pub. Co., Texas, 6595:115-117

Waluyo, L. 2008. Teknik Metode Dasar Dalam Mikrobiologi. UMM Press. UPT Penerbit Universitas Muhammadiyah Malang.

Wenti M.J.S. 2012. Oil Sludge dengan Variasi Lama Waktu Inkubasi dan Jenis Konsorsium Bakteri Yang Diisolasi Dari Lumpur Pantai Kenjeran. Departemen Biologi Universitas Airlangga.

Widjajanti H., I. Anas, N. Gofar, M.R. Ridho. $2010 . \quad$ Formulasi
Konsorsium Kapang dan Bakteri Hidrokarbonoklastik Asal Kawasan Mangrove Tercemar Minyak Bumi dan Potensinya dalam Biodegradasi Hidrokarbon Minyak Bumi. Prosiding Integrated Lowland Development and Management. Universitas Sriwijaya, Palembang. C7-1. ISBN 978-979-25-8652-7

Zam, S. A. 2010. Biodegradation of Diesel Oil Production of Fatty Acid Esters by a Newly Isolated Pseudomonas citronellolis KHA. Wolrd Journal of Microbiology and Bio 2570 